\title{
Calcitonin negative medullary thyroid cancer in ectopic thyroid tissue: a rare diagnosis in an unusual location
}

\author{
Gareth Montgomery, Laurence Collins (D) , Caroline Coghlin, Ramzan Ullah
}

ENT Surgery, Royal Victoria Hospital, Befast, UK

\section{Correspondence to} Laurence Collins; collins.laurence@doctors.org.uk

Accepted 1 July 2020
Check for updates

(c) BMJ Publishing Group Limited 2020. No commercial re-use. See rights and permissions. Published by BMJ.

To cite: Montgomery G, Collins L, Coghlin C, et al. BMJ Case Rep 2020:13:e236865 doi:10.1136/bcr-2020236865

\section{SUMMARY}

Medullary thyroid cancer is an aggressive form of thyroid cancer arising from parafollicular C cells. Calcitonin (CT) is a specific and sensitive biochemical marker which typically aids primary diagnosis and disease surveillance following treatment. There are rare cases of calcitonin negative medullary thyroid cancer (CNMTC) documented in the literature; however, to our knowledge, this case is the first report of CNMTC arising in ectopic thyroid tissue. We report a case of a 45-year-old man who attended his primary care physician with painless anterior neck swelling. In the absence of CT secreting disease, we have demonstrated the investigative process and the importance of immunohistochemical analysis to achieve a diagnosis. We also consider the challenges of monitoring disease recurrence in the absence of reliable biochemical markers.

\section{BACKGROUND}

Medullary thyroid cancer (MTC) is a neuroendocrine tumour derived from the malignant transformation of parafollicular C cells. It represents $1 \%-10 \%$ of thyroid cancer, with a mean survival of 8.6 years and a 10 -year survival rate between $69 \%$ and $89 \% .^{12}$

Approximately $75 \%$ of cases are sporadic. The remaining $25 \%$ are hereditary secondary to RET proto-oncogene germline mutation which is associated with multiple endocrine neoplasia (MEN) type $2 .^{2}$

Calcitonin (CT) and carcinoembryonic antigen (CEA) levels are typically elevated in MTC and consequently may be used as diagnostic biochemical markers and as markers of disease recurrence or progression. In particular CT, a 32 amino acid linear polypeptide, is considered a highly sensitive and specific biochemical marker owing to its secretion by parafollicular $\mathrm{C}$ cells. ${ }^{3}$ The concentration of serum CT will reflect the mass and activity of $\mathrm{C}$ cells. ${ }^{4}$ CEA is less reliable and may be in the normal range in patients with advanced, metastatic MTC. ${ }^{5}$ Like other neuroendocrine tumours, MTC can also produce a range of relevant biomarkers, such as procalcitonin (Pro-CT), neuron-specific elonase and chromogranin $\mathrm{A}(\mathrm{CgA}){ }^{1}$

Calcitonin negative medullary thyroid cancer (CNMTC) has been described in the literature; however, it is considered rare and often proves to be a challenging clinical and pathological diagnosis.
Moreover, this case describes CNMTC located in ectopic thyroid tissue. Thyroid ectopy has a reported incidence of 1 in $10000 .^{6}$ In reported cases of ectopic thyroid cancer, papillary carcinoma is most common, while medullary carcinoma is the rarest form. ${ }^{7}$ To the best of our knowledge, this is the first recorded case of a CNMTC identified in ectopic thyroid tissue in the English Literature.

\section{CASE PRESENTATION}

A 45 -year-old man presented to his primary care physician complaining of progressive anterior neck swelling, which he had experienced over the course of several months. He had a background of severe psoriatic arthritis for which he had trialled numerous biological medications. Other relevant past medical history included type 2 diabetes which was managed with oral antihyperglycaemic medication.

At presentation, he did not describe neck pain, dysphagia, dysphonia or compressive airway symptoms. He was an ex-smoker but had no other red flag symptoms, no iodine exposure, nor family history of thyroid disease.

\section{INVESTIGATIONS}

Routine ultrasound of the neck was requested prior to interaction with an ENT Specialist. This ultrasound demonstrated a $25 \times 15 \mathrm{~mm}$ hypoechoic heterogeneous mass, thought to be an enlarged lymph node, located at the inferior aspect of the

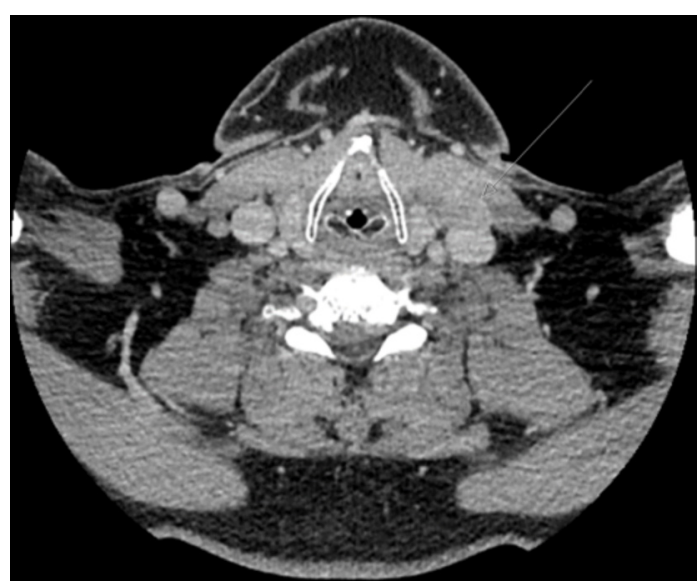

Figure 1 Axial CT image demonstrating the mass located adjacent and separate to the left thyroid lobe. 


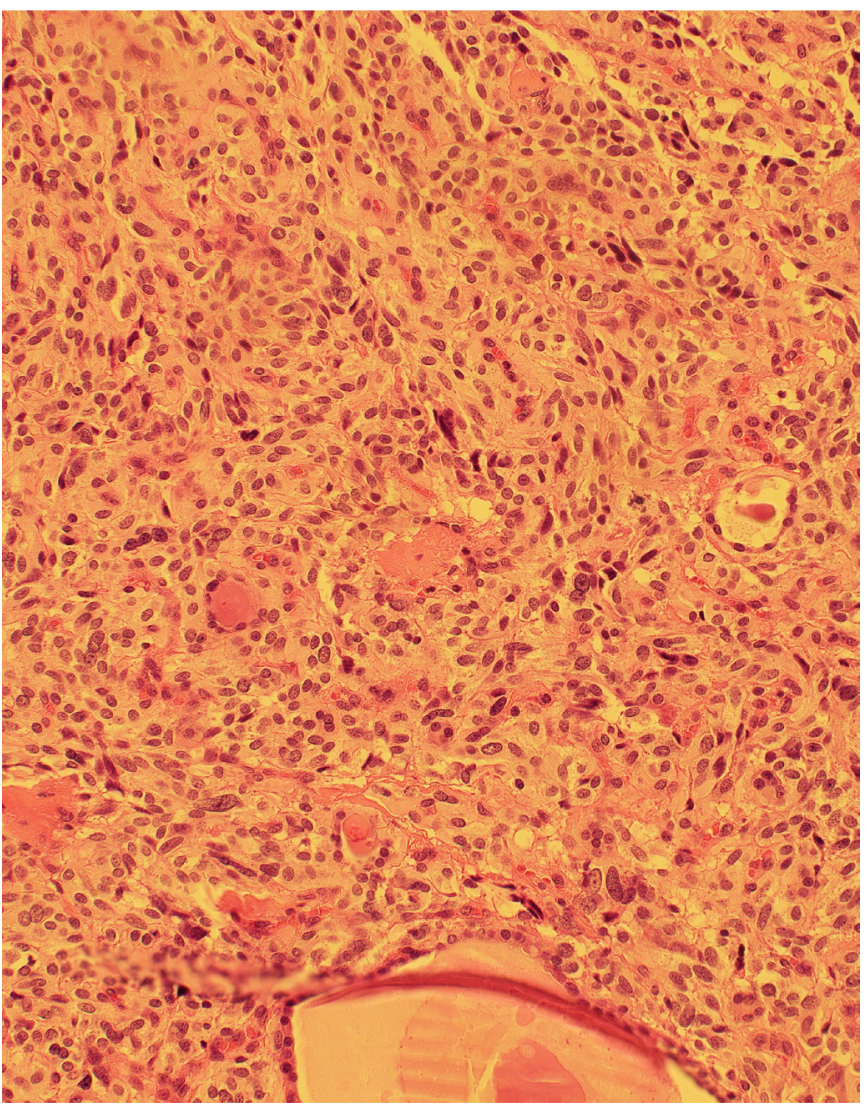

Figure 2 H\&E staining showing entrapped thyroid follicles and the solid tumour cells.

left jugular chain, which precipitated further investigation. An ultrasound-guided core biopsy suggested the possibility of a spindle cell tumour with neuroendocrine differentiation. Although the possibility of a CNMTC was raised, it was not possible to be definitive on the basis of the limited tissue submitted for pathological examination.

Relevant blood investigations showed normal thyroid function, CT $<5.0$, CEA 4.4 and chromogranin A $<1$, (all normal range). Urinary catecholamines and urinary normetanephrine returned normal excluding a phaeochromocytoma, and therefore potential MEN.

CT imaging of neck, chest, abdomen and pelvis demonstrated a $2.3 \times 1.7 \mathrm{~cm}$ mass in the left supraclavicular fossa located at the inferior aspect of the jugular chain and adjacent to normalappearing thyroid gland (figure 1). No other significant findings were identified.

Following a discussion of the case at the regional head and neck multidisciplinary team meeting (MDM) the patient proceeded to a left level IV lymph node excision.

Histological diagnosis was deemed challenging owing to the unusual combination of morphological and immunohistochemical features. Several opinions were sought including that of an external specialist endocrine pathologist.

Morphologically, the lesion consisted largely of spindle-shaped cells arranged in sheets or a nested configuration. Entrapped colloid producing thyroid follicles were present, mainly at the periphery of the lesion, but also scattered throughout (figure 2).

Immunohistochemical staining confirmed that the tumour cells were diffusely positive for TTF-1, although with a weaker intensity than that of the entrapped thyroid follicles (figure 3). Cytokeratin stains and the neuroendocrine markers; chromogranin,

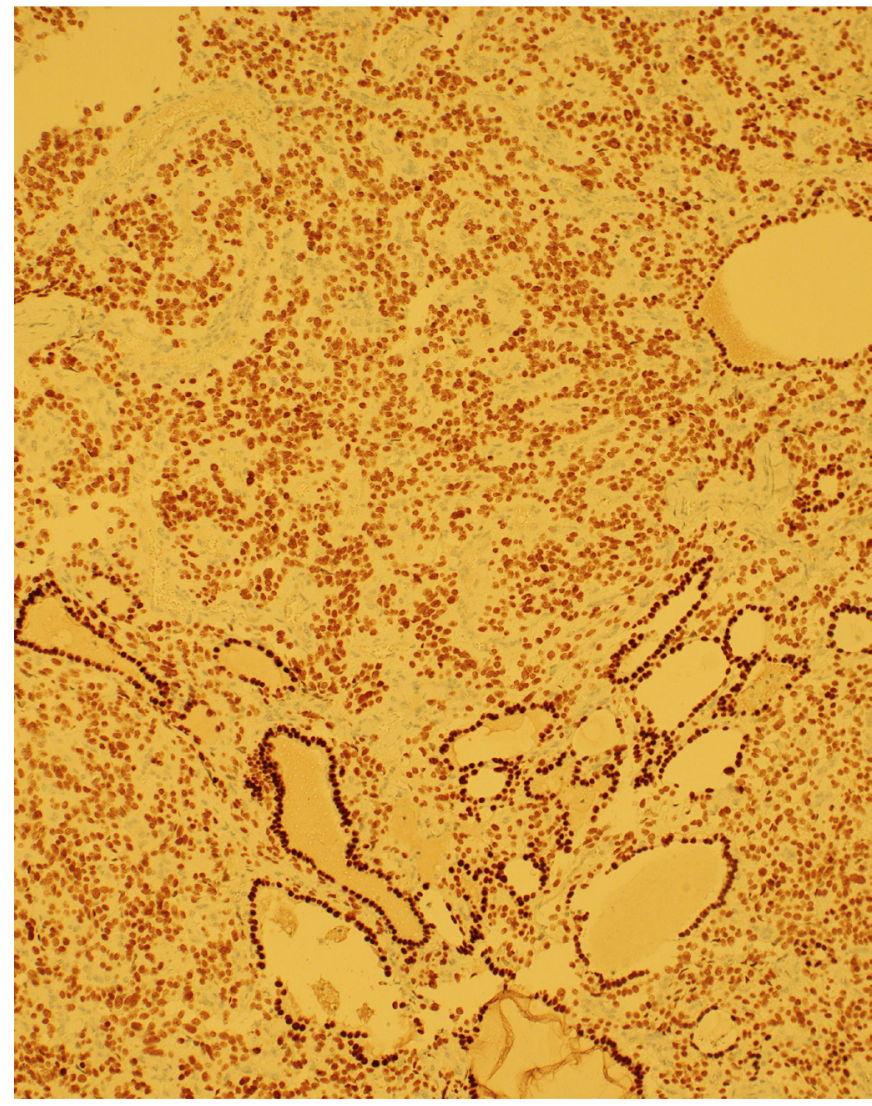

Figure 3 TTF-1 shows two-tone staining of the entrapped follicles (stronger) and the tumour (weaker).

synaptophysin and CD56 also stained positively (figure 4). CEA demonstrated patchy positivity in the tumour cells while CT, S100 and GATA3, were negative. Thyroglobulin highlighted the entrapped follicles, but was negative elsewhere in the tumour.

The combination of the morphological appearances as well as the location in level IV adjacent to the thyroid gland was, overall, consistent with that of CNMTC arising in ectopic thyroid tissue. A diagnosis of a paraganglioma offered a plausible differential, however the strong cytokeratin expression, focal CEA positivity, lack of GATA3 staining and lack of any discernible sustentacular cell meshworks on S100 protein staining helped to exclude this as a diagnostic possibility.

\section{TREATMENT}

This gentleman's case was discussed at head and neck and endocrine MDMs throughout the course of investigation and management. Following pathological diagnosis, it was recommended that he should proceed to total thyroidectomy, bilateral level II, III, IV neck dissection, and level VI neck dissection for nodal clearance.

The recommended procedure was performed and was uncomplicated. The patient was discharged on day 2 postoperatively after drain removal and was commenced on levothyroxine as per local guidelines following thyroidectomy.

\section{OUTCOME AND FOLLOW-UP}

Aside from the CNMTC in ectopic thyroid tissue, the histopathological examination found no further evidence of malignancy within the eutopic thyroid or any lymph nodes yielded during neck dissection. There was no evidence of $\mathrm{C}$ cell hyperplasia. This patient should undergo lifelong surveillance; however, the 


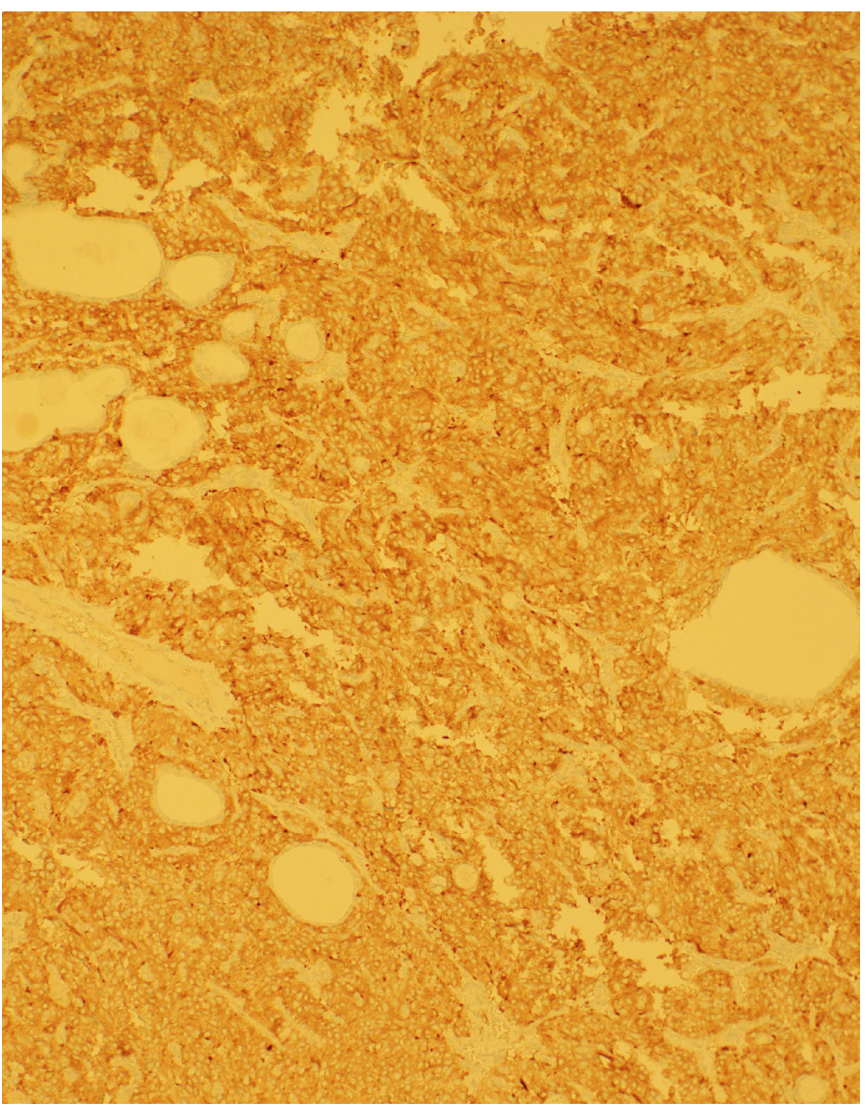

Figure 4 Synaptophysin is one of three neuroendocrine markers (others were chromogranin and CD56) which stained positively and confirmed that this tumour showed neuroendocrine differentiation.

lack of positivity of serum biomarkers makes this challenging. Guidelines would recommend genetic testing for RET mutation and onward referral has been made regarding this. ${ }^{8}$

\section{DISCUSSION}

This case presents the diagnostic challenge of an uncommon disease located in a rare location; however, for the patient, it is an important pathology to recognise.

MTC is an aggressive form of thyroid cancer, which may present with advanced disease. The majority of cases are sporadic in nature. Patients will frequently present with lymph node involvement and 20\% will have distant metastases. Early identification of disease is crucial as the mainstay of treatment with curative intent is surgical resection. ${ }^{9} 10$

The British Thyroid Association guidelines 2014 recommend that all patients with disease $>5 \mathrm{~mm}$ should undergo total thyroidectomy and level VI dissection with further neck dissection as indicated by nodal involvement. They also recommend that RET positive family members should be offered prophylactic thyroidectomy. ${ }^{8}$

Serum CT is considered the main diagnostic aid for MTC. It is recognised that measurement of this biomarker can allow earlier diagnosis than with imaging and fine needle aspiration (FNA). ${ }^{4}$ In our case, not only was serum CT negative, but it was also shown to be negative on immunohistochemical staining of excised tissue. Immunohistochemistry is crucial in the diagnosis of CNMTC with particular attention given to markers shown in the investigations above.

Positivity of TFF-1, a transcription factor regulating the expression of thyroid-specific genes could be highly suggestive of a thyroid tumour and is often detected in both MTC and CNMTC. ${ }^{11}$ A recent literature review compared results from 51 cases with CNMTC. This revealed on staining that almost half of the cases showed positivity for CT and CEA, and that 41 out of 43 tested cases showed positivity of $\mathrm{CgA} .^{2}$ Our case specimen was negative for CT, but showed positivity for CEA, chromogranin and TTF-1.

As well as diagnostic difficulties, follow-up surveillance will prove challenging as CT, which is used as an indicator of disease recurrence in MTC, cannot be relied on in CNMTC. Pro-CT and CT gene-related peptide (CGRP) are new alternative biomarkers which have shown diagnostic value in non-secretory MTC. ${ }^{1}$ Pro-CT is the precursor of CT and has been shown to be a sensitive, reliable alternative to CT and is currently of most diagnostic use. ${ }^{4}$ CGRP is secreted by MTC but also non-neoplastic C cells, and therefore may be of most use as an adjunct to diagnosis.

\section{Learning points}

- The possibility of an ectopic thyroid cancer in the setting of normal thyroid gland tissue should be considered in the differential diagnosis of a pathological mass in the neck.

- Red flag referral to tertiary level care is essential when an incidental neck nodule is identified.

- Calcitonin negativity does not entirely exclude medullary thyroid cancer and if medullary thyroid cancer is suspected, then further immunohistochemical evaluation is necessary.

- Further research is required to establish a diagnostic protocol for calcitonin negative medullary thyroid cancer and suitable post-treatment biochemical marker surveillance.

Contributors GM and LC wrote the text (GM was primary author). Histology and interpretation provided by $\mathrm{CC}$, also amended the text. Case report reviewed and edited by RU.

Funding The authors have not declared a specific grant for this research from any funding agency in the public, commercial or not-for-profit sectors.

Competing interests None declared.

Patient consent for publication Obtained.

Provenance and peer review Not commissioned; externally peer reviewed.

\section{ORCID iD}

Laurence Collins http://orcid.org/0000-0003-0895-2244

\section{REFERENCES}

1 Gambardella C, Offi C, Patrone R, et al. Calcitonin negative medullary thyroid carcinoma: a challenging diagnosis or a medical dilemma? BMC Endocr Disord 2019;19:45.

2 Gambardella C, Offi C, Clarizia G, et al. Medullary thyroid carcinoma with double negative calcitonin and CEA: a case report and update of literature review. BMC Endocr Disord 2019;19:103.

3 Sand M, Gelos M, Sand D, et al. Serum calcitonin negative medullary thyroid carcinoma. World J Surg Oncol 2006:4:97.

4 Giovanella L, Imperiali M, Piccardo A, et al. Procalcitonin measurement to screen medullary thyroid carcinoma: a prospective evaluation in a series of 2705 patients with thyroid nodules. Eur J Clin Invest 2018:48:e12934.

5 Woliński K, Kaznowski J, Klimowicz A, et al. Diagnostic value of selected biochemical markers in the detection of recurrence of medullary thyroid cancer - comparison of calcitonin, procalcitonin, chromogranin A, and carcinoembryonic antigen. Endokrynol Pol 2017:68:434-7.

6 Klubo-Gwiezdzinska J, Manes RP, Chia SH, et al. Clinical review: Ectopic cervical thyroid carcinoma--review of the literature with illustrative case series. J Clin Endocrinol Metab 2011;96:2684-91.

7 Choi J-Y, Kim J-H. A case of an ectopic thyroid gland at the lateral neck masquerading as a metastatic papillary thyroid carcinoma. J Korean Med Sci 2008;23:548.

8 pp.Mitchell AL, Gandhi A, Scott-Coombes D, et al. Management of thyroid cancer: United Kingdom national multidisciplinary guidelines. J. Laryngol. Otol. 2016;130:\$150-60 
9 Stamatakos M, Paraskeva P, Stefanaki C, et al. Medullary thyroid carcinoma: the third most common thyroid cancer reviewed. Oncol Lett 2011;2:49-53.

10 Costante G, Meringolo D, Durante C, et al. Predictive value of serum calcitonin levels for preoperative diagnosis of medullary thyroid carcinoma in a cohort of 5817 consecutive patients with thyroid nodules. J Clin Endocrinol Metab 2007;92:450-5.
11 Cai H-J, Wang H, Cao N, et al. Calcitonin-negative neuroendocrine tumor of the thyroid with metastasis to liver-rare presentation of an unusual tumor: a case report and review of literature. World I Clin Cases 2020;8:179-87.

Copyright 2020 BMJ Publishing Group. All rights reserved. For permission to reuse any of this content visit

https://www.bmj.com/company/products-services/rights-and-licensing/permissions/

BMJ Case Report Fellows may re-use this article for personal use and teaching without any further permission.

Become a Fellow of BMJ Case Reports today and you can:

- Submit as many cases as you like

- Enjoy fast sympathetic peer review and rapid publication of accepted articles

- Access all the published articles

- Re-use any of the published material for personal use and teaching without further permission

Customer Service

If you have any further queries about your subscription, please contact our customer services team on +44 (0) 2071111105 or via email at support@bmj.com.

Visit casereports.bmj.com for more articles like this and to become a Fellow 